\title{
Handling Water Leaking on The Turbine Pit ULPLTA Bakaru due to Damage of the Guide Vane Part using Automatic Method with Motorized Valve
}

\author{
Mochamad Marte Ardhianto, ${ }^{1, a, *}$ and Rudi Sumarwanto ${ }^{1}$ \\ ${ }^{1}$ PT. PLN (Persero) Pusat Pendidikan dan Pelatihan (UPDL)/Center for Education and Training, Makassar \\ a, ${ }^{*}$ marte@pln.co.id (Corresponding Author)
}

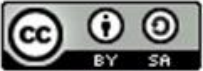

Abstract-The Bakaru PLTA is the largest hydroelectric power plant in South Sulawesi with a capacity of $126 \mathrm{MW}$. In operation, the Bakaru hydropower plant consists of 2 units. However, not all units operate normally, such as unit 2. In unit 2, there is a leak that occurs in the Turbine Pit. This leak is caused by abrasion of the u-packing guide vane. With a leak in the turbine pit, more approaches are needed to dispose of the water in the turbine pit to the pit drainage. Which later developed into an infusion system that utilizes gravity to discharge water from the turbine pit in basement 2 to the drainage pit in basement 3. However, in its development, it turns out that the volume of water discharged cannot be controlled so that, it can cause a condition where one day the infusion hose does not flow and causes an increase in the water level in the turbine pit. The purpose of this study was to determine the optimal method of handling the increase in water level in the turbine pit so that unit trips do not occur caused by the increase in the water level in the turbine pit. Finally, it is interesting to discuss and find a solution by relocating the handling of leaks by using an automatic method with a motorized valve by installing a Motorized Valve on the Turbine Pit, so there are financial and non-financial benefits to be obtained. From the results of using the automatic method with a motorized valve, the results obtained are faster cycle times for handling leaks in the turbine pit so there is no stop unit due to leakage disturbances in the turbine pit.

Keywords-Motorized Valve; Leakage; Turbine Pit.

\section{Introduction}

The Bakaru PLTA is a hydroelectric power station that has a vertical shaft engine design with a Francis turbine type. Located in Ulusaddang Village, Lembang District, Pinrang Regency, South Sulawesi, with a capacity of 2 x 63 MW Bakaru Hydroelectric Power Plant is a highly reliable generator that is expected to supply electricity to the $150 \mathrm{KV}$ interconnection system of South Sulawesi and West Sulawesi [1]. Conditions in Unit 2 of the Bakaru hydropower plant are water leaks in the turbine pit, where this condition is very vulnerable because it can cause the oil level in the turbine bearing become low due to the vacuum in the turbine bearing oil tank, and this low oil level condition can cause the unit to trip during operation. This leak is caused by abrasion of the u-packing guide vane.
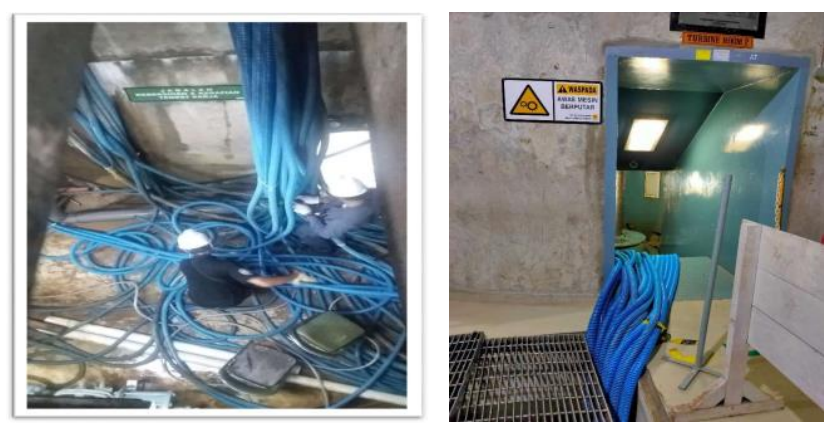

Figure 1. Leakage conditions in the turbine pit

In the case of a turbine pit leak, it is necessary to find a way to dispose of the water in the turbine pit to the drainage pit. This increase in the turbine level is dangerous for the unit, because water can enter the turbine bearing housing so that the oil mixes with the water which causes high bearing temperatures and causes trips and causes equipment damage to the bearings. Based on these problems, a tool is needed that can overcome water leakage in the turbine pit, namely by using a sensor system method that is connected to Motorized which will operate automatically if the state of the water level in the Turbine Pit has exceeded a predetermined height. 
Prevention of trips that occur in unit 2 which also results in equipment damage can be reduced to a minimum, with the hope that the Bakaru ULPLTA can operate optimally to increase PLN's revenue given the small BPP ULPLTA Bakaru.

\section{A. Hydroelectric Power Plant}

River flows with such a large amount of water discharge are accommodated in reservoirs that are supported in the form of dam buildings, the Bakaru hydropower plant is a type of large dam with concrete construction (concrete gravity dams). Then the water is flowed through a filter to the Power Intake. Then it enter the rapid pipe or often known as Penstock which the functions to drain the water from the delivery channel or reservoir pool from the water intake to the turbine, which has a sharp slope position, which aims to obtain water potential energy (water pressure) to rotate the water turbine. The end of the tunnel is connected with a penstock which has a length of $1,698 \mathrm{~m}$. The kinetic energy of water undergoes a process of increasing along with the decrease in the height of the penstock and the decrease in silence so that the water pressure to rotate the turbine is even greater. Converting potential energy into kinetic energy, at the end of the Penstock pipe the Main Inlet Valve is installed. To flow water to the turbine, the main valve will be closed automatically in the event of a disturbance or it is stopped or repairs/maintenance of the turbine are carried out. Water that already has high pressure and velocity (kinetic energy) is converted into mechanical energy by flowing through the guide fins (fixed blades) which will push the Runner blades on the turbine with a water flow capacity of $22.5 \mathrm{~m} / \mathrm{s}$ (1 unit). On the turbine, the falling force of the water that pushes the propeller causes the turbine to rotate, most water turbines are like windmills, by replacing the function of the wind thrust to rotate the propellers, water is replaced by water to turn the turbine. Furthermore, the turbine converts the kinetic energy caused by the falling force of the water into mechanical energy. The generator is connected to the turbine through rotating gears so that when the turbine blades rotate, the generator rotates too. The generator then converts the mechanical energy from the turbine into electrical energy. Electricity in the generator occurs because the copper coil which is given an iron core is moved (rotated) near the magnet. Alternating magnetic poles will move the electrons in the copper coil so that at the ends of the copper wire electricity will come out which then generates electricity. Water turbines are mostly like windmills, by replacing the function of the wind thrust to turn the blades replaced by water to turn the turbine. Furthermore, the turbine converts the kinetic energy caused by the falling force of the water into mechanical energy. The generator is connected to the turbine through rotating gears so that when the turbine blades rotate, the generator rotates as well. The generator then converts the mechanical energy from the turbine into electrical energy.

The water that comes out through the TailRace will then flow back into the river. The electric power generated by the generator is still low, therefore the voltage is first raised with the main transformer. For efficient distribution of energy from the generator to the load center, the high voltage is then regulated/shared in the Switchyard. And then it is channeled/interconnected to the electric power system through a high-voltage line wire [2].

\section{B. Bakaru Water Turbine Performance}

The performance of a water turbine is generally measured from the operating pattern and the efficiency level of the power produced by a turbine based on the amount of water flow given. And for some types of turbines have different characteristics, which can be seen in the Table 1 .

Table 1. Operating Range of Hydraulic Turbine [3]

\begin{tabular}{|c|c|c|c|c|c|c|}
\hline Reaction Rate & Turbine Type & \begin{tabular}{|c|} 
Specific speed \\
$\mathrm{n}_{4}$
\end{tabular} & \begin{tabular}{|c|} 
Turbine Porrer \\
P
\end{tabular} & \begin{tabular}{|c|} 
Turbine Head \\
H
\end{tabular} & \begin{tabular}{|c|} 
Turbine Discharge \\
$Q$
\end{tabular} & $\begin{array}{l}\text { Nax. Turbine Efficiency } \\
\text { (Fuction of }_{9} \text { and porrer) }\end{array}$ \\
\hline $\begin{array}{c}\text { Ratio betrieen nor } \\
\text { converted net } \\
\text { head into kinetic } \\
\text { energy before the } \\
\text { runner and } \\
\text { turbine net head }\end{array}$ & $\begin{array}{c}\text { Most frequent } \\
\text { type }\end{array}$ & $n \times \frac{\sqrt{Q}}{H^{0.75}}$ & [MN] & [m] & {$\left[\mathrm{m}^{3} / \mathrm{s}\right]$} & $\begin{array}{l}\text { Ratio betreen mechanical } \\
\text { porrer at the coupling and } \\
\text { arailable hydraulic powrer } \\
\eta=P /(g \times H \eta) \times(\rho \times Q)=\eta, \eta_{n}\end{array}$ \\
\hline$>0$ & Pelton & $5<n_{q}<20$ & $1 \div 420$ & $200 \div 1800$ & $0.15+50$ & $\leq 92,5 \ldots .$. \\
\hline $0.25 \div 0,70$ & Francis & $25<\mathbf{M}_{\mathbf{q}}<100$ & $1 \div 850$ & $20 \div 600$ & $1+825$ & $\leq 95,5 \ldots$ \\
\hline$<1$ & Kaplan & $>80$ & $1+160$ & $2+90$ & $10 \div 800$ & $\leq 96 \ldots . .$. \\
\hline
\end{tabular}

However, from a corporate or business perspective that is engaged in energy generation, one of the indicators for assessing the performance of a 
generating unitis the ability to meet the production of electrical energy according to the capacity or installed power of the unit. This indicator is often referred to as the capacity factor of the generating unit which is measured over a certain period of time.

\section{Guide Vane Operating Mechanism}

Guide vane is part of the water turbine which functions as a regulator of the inflow of water from the spiral casing to the runner blade so that the water entering the runner has an even discharge.

The movement of the guide vane is regulated by an equipment mechanism in the governor. Guide vane itself has an operating mechanism to open and close (Guide vane Mechanism). The function of the guide vane mechanism is to transmit the hydraulic force and pressure from the guide vane servomotor evenly to each guide vane. To adjust each guide vane opening, a link pin is provided as a pin that connects the guide vane operating ring and each guide vane link. To transmit the shear force in the movement of the guide vane there is a shear pin. For example, the guide vane is blocked by a foreign object in the water, the shear pin will be damaged by transmitting the operating force to the guide vane, and the movement of the operating mechanism of the remaining guide vane can be continued. To prevent the blocked guide vane from sliding and damaging the guide vane or other parts, there is a friction device that performs the following functions on each guide vane. The guide vane arm is connected to the spindle using a wrench and guide vane lever. Normally, the guide vane lever is connected to the guide vane arm using a shear pin. The force generated during operation is transmitted from the guide vane lever to the guide vane arm and to the shaft via the shear pin. There is a friction device that performs the following functions on each guide vane. The guide vane arm is connected to the spindle using a wrench and guide vane lever. Normally, the guide vane lever is connected to the guide vane arm using a shear pin. The force generated during operation is transmitted from the guide vane lever to the guide vane arm and to the shaft via the shear pin. There is a friction device that performs the following functions on each guide vane. The guide vane arm is connected to the spindle using a wrench and guide vane lever. Normally, the guide vane lever is connected to the guide vane arm using a shear pin. The force generated during operation is transmitted from the guide vane lever to the guide vane arm and to the shaft via the shear pin.

On the spindle guide vane there is an upper bushing that is useful as a spindle holder so that it does not run away when the guide vane mechanism

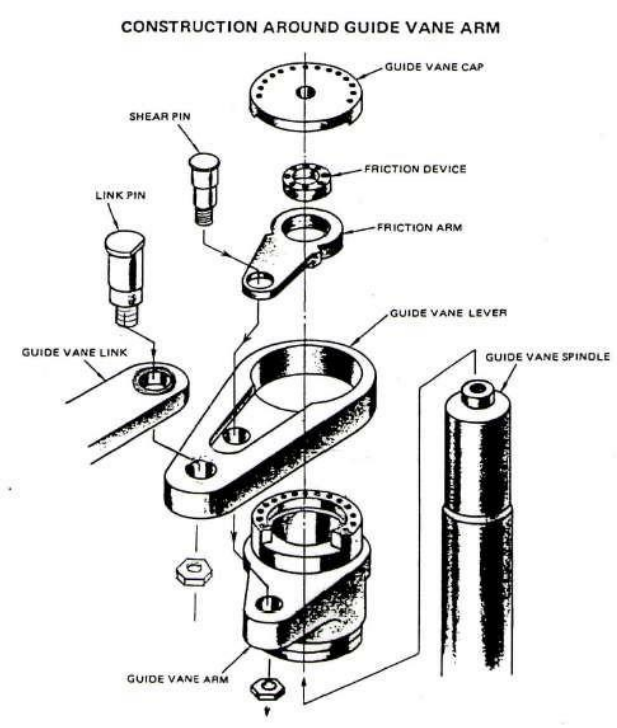

operates. In addition, the bushing contains a material in the form of carbon graphite which functions to lubricate the spindle. If the shear pin is damaged, the guide vane lever is free from the guide vane arm,

Figure 2. Construction of Guide vane Arm

thus separating the guide vane from being blocked by foreign objects. Next, the friction device and Friction arm start to function. The friction device is a ring that connects the spindle and the friction arm or is called a friction connection. The applied force is transmitted through the friction connection from the guide vane lever to the friction arm after the shear pin is damaged. Friction connection allows movement between spindle and friction arm, and allows movement of the guide vane operating mechanism even if the guide vane is still blocked by foreign objects. On the other hand, the friction connection prevents the isolated guide vane from 
moving erratically which could damage the guide vane and other equipment. The daily operation of the Bakaru hydropower plant as a base load with a capacity of $126 \mathrm{MW}$ with a water consumption of $44.5 \mathrm{~m}^{3} / \mathrm{s}$. The daily operating load pattern is adjusted to the conditions of the inflow discharge entering the dam. The purpose of the loading pattern is to maintain the dam elevation at a minimum elevation of $614.00 \mathrm{~m} . \mathrm{dpl}$ and a maximum elevation of 615.53 m.dpl. The existing operating pattern must pay attention to the power plant center so that the production of electrical energy produced must be in accordance with the needs and can be absorbed by consumers [4].

\section{Continuity Equation}

The continuity equation relates the velocity of a fluid at one place to another. The tangent at a point on the flow line represents the direction of the fluid velocity. None of the flow lines intersect with each other. The water tube is a collection of flow lines. In the flow tube, the fluid enters and leaves through the mouths of the tube. Fluid should not enter from the side of the tube because it can cause the intersection of flow lines. This intersection will cause steady flow.

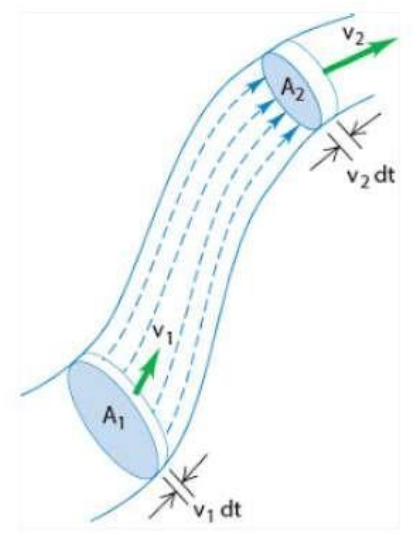

Figure 3. Illustration of Fluid Flow in a Tube

Water enters from the left end at a speed of $\mathrm{v}_{1}$ and exits at the right end at a speed of $v_{2}$. If the velocity of the fluid is constant, then in the time interval $t$ the fluid has traveled a distance $\Delta \mathrm{s}_{1}=\mathrm{v}_{1} \times \Delta \mathrm{t}$. If the cross-sectional area of the left cylinder is $\mathrm{A}$, then the mass in the shaded region is:
$\Delta \mathrm{m}_{1}=\rho_{1} \cdot \mathrm{A}_{1} \cdot \Delta \mathrm{s}_{1}=\rho_{1} \cdot \mathrm{A}_{1} \cdot \mathrm{v}_{1} \cdot \Delta \mathrm{t}$

Likewise for the fluid located at the right end of the tube, its mass in the shaded region is:

$\Delta \mathrm{m}_{2}=\rho_{2} \cdot \mathrm{A}_{2} \cdot \Delta \mathrm{s}_{2}=\rho_{2} \cdot \mathrm{A}_{2} \cdot \mathrm{v}_{2} \cdot \Delta \mathrm{t}$

Because the flow is steady and mass is constant, the mass entering section $A_{2}$ must equal the mass entering section $\mathrm{A}_{2}$. Therefore the equation becomes:

$$
\begin{aligned}
\Delta \mathrm{m}_{1} & =\Delta \mathrm{m}_{2} \\
\rho_{1} \cdot \mathrm{A}_{1} \cdot \mathrm{v}_{1} & =\rho_{2} \cdot \mathrm{A}_{2} \cdot \mathrm{v}_{2}
\end{aligned}
$$

$\mathrm{A}_{1} \mathrm{v}_{1}=\mathrm{A}_{2} \mathrm{v}_{2}$

Where :

$A_{1}$ is cross-sectional area $1\left(\mathrm{~m}^{2}\right)$

$\mathrm{A}_{2}$ is cross-sectional area $2\left(\mathrm{~m}^{2}\right)$

$\mathrm{V}_{1}$ is the fluid flow velocity at cross section $1(\mathrm{~m} / \mathrm{s})$

$\mathrm{V}_{2}$ is fluid flow velocity at cross section $2(\mathrm{~m} / \mathrm{s})$

$\rho_{1}$ is the density of fluid flow at cross section 1 $\left(\mathrm{kg} / \mathrm{m}^{3}\right)$

$\rho_{2}$ is the density of the fluid flow at cross section 2 $\left(\mathrm{kg} / \mathrm{m}^{3}\right)$

\section{Methodology}

The data collection of this research is located at the Bakaru Hydroelectric Power Plant. The data is obtained from daily recording data, monthly reports and business reports. This research data collection was carried out by taking case studies at the Bakaru Hydroelectric Power Plant in the range of 2018 to 2020. As for the parameters used for data collection are data on the number of SR disturbances (service requests) increasing the water level in the turbine pit and data on trip unit disturbance reports due to the increase in the water level in the turbine pit.Data retrieval is obtained from the operations section. Recording data in the control room of the Bakaru hydropower plant, in the form of digital record data and printed data records within a period of 6 months.

After getting the recorded data, the required data is selected. The flow chart of this research work can be shown as follows: 


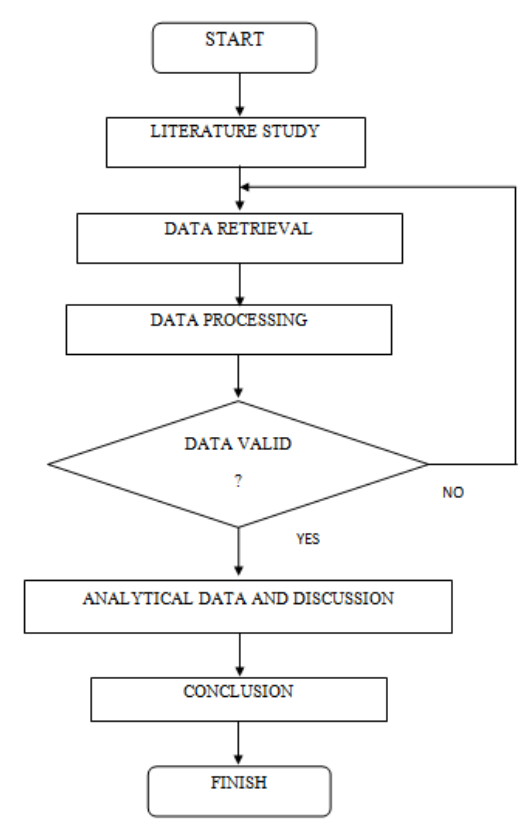

Figure 4. Flowchart of research stages

\section{Discussion and Results}

\section{A. Root Cause Problem Solving}

Root Cause Problem Solving (RCPS) is a tool for problem solving initiatives by identifying root causes that can lead to repeated failures until the correct corrective steps are obtained. There are 4 stages of RCPS, namely defining the problem, structuring the problem, prioritizing the problem and planning action [5].

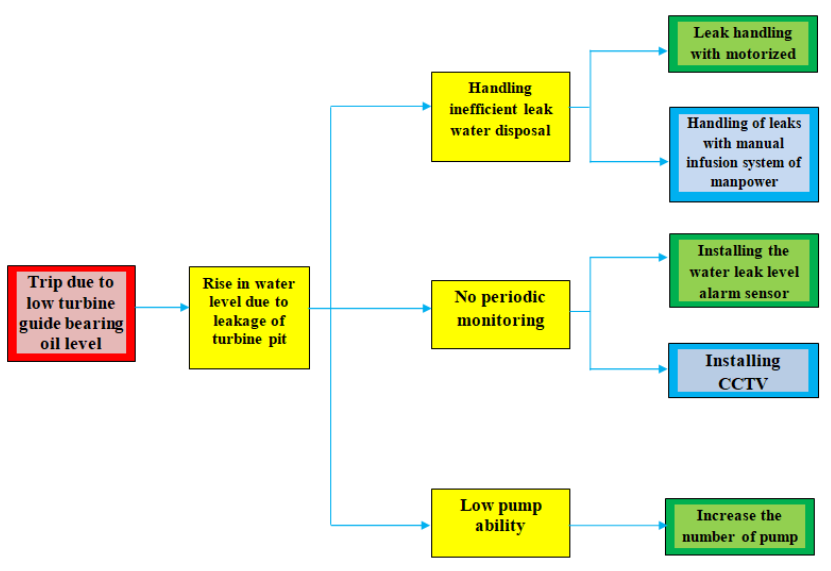

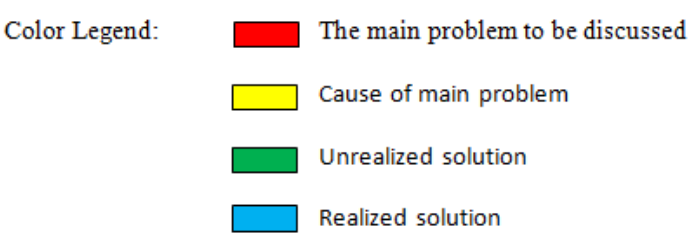

Figure 5. Turbine pit Water Level Handling RCPS

Based on the action plan that has been determined in the RCPS, a solution or idea generation is obtained with several notes, namely:

1. Motorized valve installation, this solution has a high impact and easy implementation. This solution is intended to prevent tripping due to low levels of Turbine bearing oil with automatic operation of the tool.

2. Installation of alarm sensors has an easy implementation, but in terms of impact it is still low.

3. Increasing the number of pumps has a moderate impact, this is because the pump is not able to continue to work continuously, besides that in terms of implementation, it requires quite a lot of space.

Each problem has a priority scale, so that it can be determined to solve the problem.

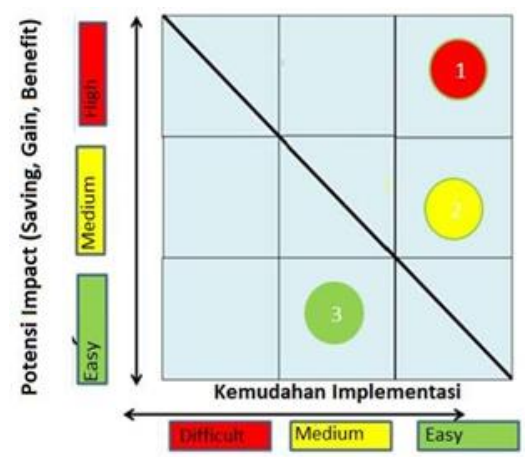

Figure 6. Turbine pit Water Level Treatment Solution Priority Matrix.

From the priority matrix, making Motorized installation is the most appropriate solution which has a high impact and is easy to implement. 


\section{B. Motorized Valve Design}

Installing the motorized valve is very easy, first the motorized valve is installed with a butterfly valve and then a header is attached which has 6 valves as suction. This header section which functions to suck water is useful as an initial impetus for the occurrence of a suction force that utilizes the force of gravity. After it is felt that there is enough suction force, the motor can be remotely closed or opened. This can be done by the operator from the control room when he sees that the water level in the turbine pit has exceeded the normal limit [6].

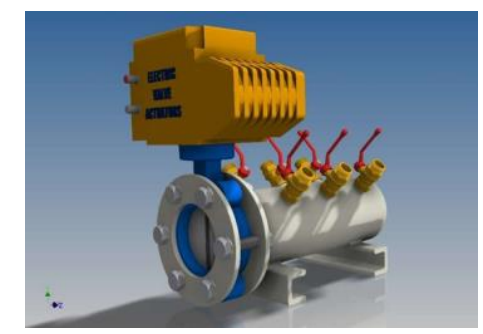

(a)

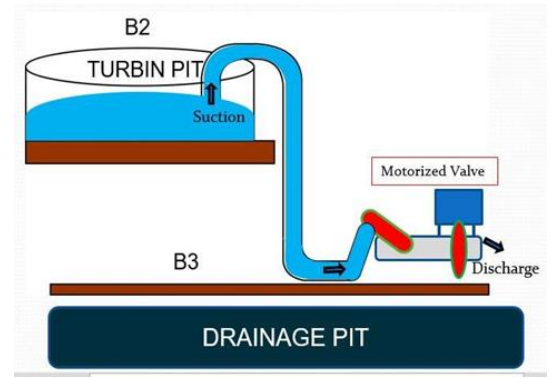

(b)

Figure 7. (a) Motorized valve design (b) Motorized valve working principle schematic [7]

After using the Motorized valve:

1. No water preparation required for trigger from Jet Pump

2. No disassembly and rearrangement of the hose is required.

3. The flushing officer does not need to be on standby, only needs to come down occasionally if there is a clogged hose problem.

4. Reducing the risk of work accidents because reducing it does not make officers have to be on standby at B3.

\section{Cycle Time Using Motorized Valve}

Cycle time for handling leaks in the Turbine pit are as follows:

1. Go down from Floor 2 to $\mathrm{B} 3 \pm 3$ minutes

2. Preparation of water for mining from Jet Pump \pm 5 minutes

3. No need Disassembly and rearrangement of hoses \pm 0 minutes Total time \pm 8 minutes to parallel units

So the total time for the preparation of the start unit to the parallel unit is \pm 8 minutes.

\section{Cycle Time Using Human Power}

Cycle time for handling leaks in the Turbine pit with human power Manual Method:

1. Go down from Floor 2 to $\mathrm{B} 3 \pm 3$ minutes

2. Preparation of water for trigger from Jet Pump \pm 10 minutes

3. Disassembly and rearrangement of hoses \pm 20 minutes Total time \pm 33 minutes to parallel units.

Therefore, the total time for the preparation of the starting unit to the parallel unit is \pm 25 minutes. The assumption is in the process of handling leakage disturbances in the turbine pit if it is accumulated in a period of one month, then every month it takes a manual flushing time of 16.5 hours, compared to using a motorized valve in one month, the time needed is 4 hours. The graph of the comparison of leak handling time can be seen in Figure 8 .

Based on Figure 8 the graph for handling leaks in the Turbine pit, it can be concluded that the leakage handling time using the Motorized valve system is 4 times faster than using the manual method. The comparison of leak handlers in the deep Turbine pit 


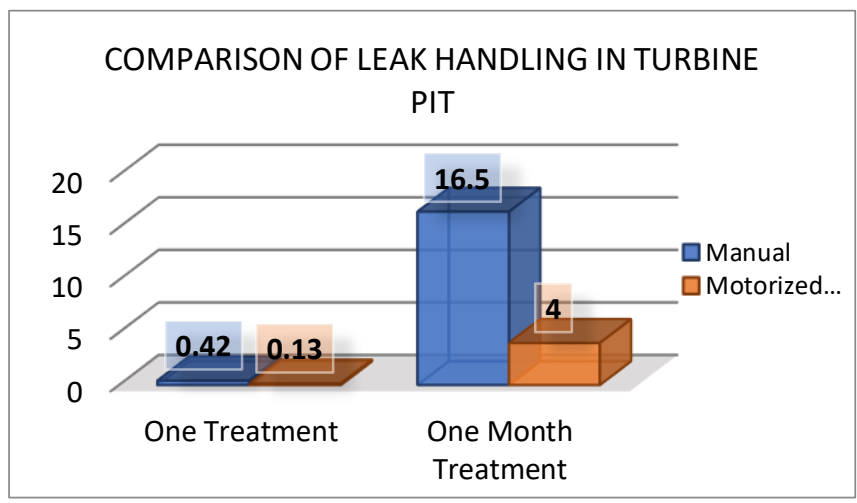

Figure 8. Graph of leak handling comparison in the Turbine pit.

is seen in table 2 which describes the conditions for handling leaks manually and using the Motorized valve system.

Table 2. Comparison of leak handling in Turbine pits

\begin{tabular}{|c|c|}
\hline Before using Motorized valve & $\begin{array}{l}\text { After using the Motorized } \\
\text { valve }\end{array}$ \\
\hline $\begin{array}{l}\text { 1. Water preparation for } \\
\text { triggering Jet Pump is } \\
\text { required }\end{array}$ & $\begin{array}{l}\text { 1. Water preparation for } \\
\text { trigger from Jet Pump } \\
\text { isn't required }\end{array}$ \\
\hline $\begin{array}{l}\text { 2. Disassembly and } \\
\text { rearrangement of the hose } \\
\text { are required }\end{array}$ & $\begin{array}{l}\text { 2. Disassembly and } \\
\text { rearrangement of the } \\
\text { hose aren't required }\end{array}$ \\
\hline $\begin{array}{l}\text { 3. Flushing officers need to } \\
\text { be on standby at B3 when } \\
\text { it is deemed necessary to } \\
\text { add a hose or replace a } \\
\text { problematic hose }\end{array}$ & $\begin{array}{l}\text { 3. The flushing officer } \\
\text { does not need to be on } \\
\text { standby, only needs to } \\
\text { come down } \\
\text { occasionally if there is a } \\
\text { clogged hose problem. } \\
\text { 4. Reducing the risk of } \\
\text { work accidents because } \\
\text { reducing it does not } \\
\text { make officers have to } \\
\text { be on standby at B3. }\end{array}$ \\
\hline
\end{tabular}

Based on table 2, it can be concluded that the handling of leaks in the Turbine pit using the Motorized valve system is more effective and safer in handling leaks in the Turbine pit.

\section{Conclusion}

In this study, the author can draw several conclusions at the Bakaru Hydroelectric Power Plant in handling water leaks at the Bakaru Pit ULPLTA turbine due to damage to the guide vane part using an automatic method with a motorized valve, namely as follows;

1. Reduce the potential for disturbances that occur and damage to generating equipment due to increased water levels in the turbine pit.

2. The time used for handling the increase in water level in the turbine pit can be saved up to 4 times faster than using the manual method.

3. Reducing the use of human labor which at the same time reduces the risk of work accidents and increases the reliability of the generator.

\section{References}

[1] Bakaru hydropower plant. Operation Report 2018-2020. Pinrang: Bakaru hydropower plant. 2020.

[2] https://www.energy.gov/eere/water/how-hydropower-works (Accessed: 10 August 2021)

[3] Cateni, Aldo. et al. Optimization of Hydro Power Plants Performance Importance of Rehabilitation and Maintenance in Particular for The Runner Profiles. In the journal Economics of Efficiency Testing and Monitoring. Italy. 2008 (On line). (http://www.ighem.org/Paper2008/03.pdf), accessed June 19, 2021).

[4] S.L. Dixon, C.A. Hall, Fluid Mechanics and Thermodynamics of Turbomachinery (Sixth Edition), Butterworth-Heinemann, 2010, Pages 217-263, ISBN 9781856177931.

[5] M. J. Ershadi, R. Aiassi, S. Kazemi, "Root cause analysis in quality problem solving of research information systems: A case study", International Journal of Productivity and Quality Management 24(2):284, January 2018.

[6] Anonymous. "Motorized control valves and actuators". https://www.danfoss.com/en/products/valves/dhs/motorized -control-valves-and-actuators/ (accessed July 10, 2021). 2019.

[7] BC Greece. "Design of a PLC-Based Digitally Controlled Motorized Valve and Monitoring its Performance Using a SCADA/HMI System", Depok: University of Indonesia. 2010. 